\title{
O discurso sobre Deus na analogia entis e a contemplação como linguagem na teologia da cruz
}

\author{
Discourse about God in analogy entis and the contemplation like \\ language in theology of the cross
}

Luiz Maria de Barros Coelho Neto ${ }^{\mathbf{1}}$

\section{Resumo}

O presente artigo se debruça sobre os limites do que é possível dizer sobre a identidade e os predicados de Deus em linguagem humana. Afirma a contribuição do discurso analógico sobre Deus, tomando como exemplo a analogia entis de Tomás de Aquino, para expressar certa proporcionalidade do Criador com suas criaturas. Ao mesmo tempo apresenta alguns de seus limites para dizer sobre a identidade mais profunda de Deus, inefável em si mesmo, mas revelado de modo todo próprio a partir da linguagem da teologia da cruz, marcada pela contemplação e pelo silêncio que comunica. Contribuirá nesse percurso a análise de textos de síntese sobre a analogia entis e argumentações advindas de dois autores vinculados à teologia da cruz: Moltmann e Edith Stein. Afirmamos que o dado revelado por Deus e captado a partir da racionalidade humana precisa ser conjugado com o dado revelado na cruz para tocar a identidade de Deus. Na primeira parte discorre sobre a teologia como discurso sobre Deus e volta-se para a analogia entis, passando em seguida a versar sobre a linguagem da teologia da cruz. Por fim, realiza-se uma síntese estabelecendo alguns dos limites da própria linguagem, da teologia ocidental clássica e a complementariedade da teologia da cruz.

Palavras-chave: analogia entis; teologia da cruz; linguagem.

\begin{abstract}
This article focuses on the limits of what is possible to say about the identity and predicates of God in human language. It affirms the contribution of the analogical discourse about God, taking as an example the Thomas of Aquinas entis analogy, to express a certain proportionality of the Creator with his creatures. At the same time, it presents some of its limits for saying about the deepest identity of God,

\footnotetext{
${ }^{1}$ Presbítero católico, Licenciado em Filosofia (2008), Bacharel em Teologia pela PUCRS (2014) e pela Pontifícia Universidade Lateranense (Roma 2014), e Mestrando em Teologia Sistemática pela Pontifícia Universidade Católica do Rio Grande do Sul, Porto Alegre, RS, Brasil.

E-mail: barroslui@gmail.com
} 
ineffable in itself, but revealed in its own way through the language of the theology of the cross, marked by contemplation and the silence it communicates. The analysis of synthesis texts on the entis analogy and arguments from two authors linked to the theology of the cross will contribute to this path: Moltmann and Edith Stein. We affirm that the data revealed by God and captured from human rationality needs to be combined with the data revealed on the cross to touch the identity of God. In the first part, he discusses theology as a discourse on God and turns to the entis analogy, then moving on to the language of the theology of the cross. Finally, a synthesis is established, establishing some of the limits of language itself, of classical Western theology and the complementarity of the theology of the cross.

Keywords: analogy entis; theology of the cross; language.

\section{Introdução}

O que é possível dizer validamente sobre Deus? Podemos discursar adequadamente sobre o inatingível e o infinito? Podemos expressar, ao menos parcialmente, o mistério inefável em palavras ou linguagens humanas? A linguagem humana é capaz de expressar validamente a realidade? Estes são alguns questionamentos norteadores para esta nossa breve pesquisa. Outras questões ainda surgem em decorrência desses, como de que maneira se pode predicar algo de Deus a partir da racionalidade e linguagem humana? E, por fim, que contribuição nos dá ao discurso sobre Deus a revelação sobrenatural a partir da teologia da cruz?

Partindo do princípio que afirma a possibilidade de o ser humano chegar ao conhecimento de Deus por via natural e racional encontrado nas afirmações de Tomás de Aquino ${ }^{2}$, é necessário que explicitemos de que maneira isso pode acontecer. Conforme o autor Christoph Böttigheimer, a teologia pode ser expressa em três formas de discurso sobre o divino: catafática, apofática e mística. Assim, o discurso sobre Deus pode ser expresso de maneira afirmativa, negativa ou metafórica [ou analógica] 3 .

\footnotetext{
2 "[...] Segundo a perspectiva de São Tomás, o grande teólogo qualificado também como Doctor humanitatis, a natureza humana é, em si mesma, aberta e boa. O homem é naturalmente capax Dei [Summa Theologiae, I-II, 113, 10; Santo Agostinho, De Trinit. XIV, 8: PL 42,1044], criado para viver em comunhão com o seu Criador." (JOÃO PAULO II. Mensagem do Papa João Paulo II aos teólogos, filósofos e peritos participantes no Congresso Internacional Tomista. Roma, 2003. Disponível em: <http://www.vatican.va/content/john-paul-ii/pt/speeches/2003/september/documents/hf_jpii_spe_20030929_congresso-tomista.pdf $>$. Acesso em: 08 de jun. de 2020).

3 "O conceito da teologia adquiriu uma importância decisiva em Dionísio Areopagita [por volta de 500 d.C.], que, no contexto de sua reflexão sobre como Deus pode ser verbalizado, distinguiu entre teologia catafática [afirmativa], apofática [negativa] e mística [especulativa]. Desde o início, a teologia cristã antiga tentou reunir a fé e o conhecimento e assim se posicionar entre o mito e o racionalismo. [...] A fé busca o conhecimento da razão para fundamentar-se a si mesma."
} 
No entanto, ainda que se possa chegar ao ponto de alguma predicação natural a respeito de Deus, isto é, que se possa dizer algo racional e analogamente sobre Deus, precisamos ir além do limite imposto pela analogia e acolher a revelação sobrenatural que é aquilo que o próprio Deus escolheu dizer sobre si mesmo em linguagem humana através de Jesus Cristo, Verbo Divino Encarnado e crucificado.

Por essas razões o presente artigo pretende responder a seguinte problemática: para falar sobre a identidade de Deus é suficiente o discurso racional da analogia entis uma vez confrontada com o dado revelado da cruz? E se estrutura da seguinte forma: apresenta-se a teologia como discurso sobre Deus, em seguida aprofunda-se a forma analógica e metafórica de expressão do discurso teológico, de modo particular aborda-se a conhecida analogia entis de Tomás de Aquino. Num segundo momento do presente trabalho, dados os limites encontrados no conhecimento natural sobre Deus se propõe uma reflexão teológica da cruz, a partir de autores como Jürgen Moltmann e Edith Stein, como proposta de uma linguagem do silêncio e da contemplação, toda própria para um conhecimento e um falar mais abrangente capaz de dizer algo sobre a identidade de Deus.

\section{A Teologia como discurso sobre Deus}

A teologia enquanto ciência hermenêutica discorre acerca de uma experiência de fé. Ela supõe a fé e a sistematiza em discurso expresso por meio de uma linguagem finita e limitada sobre um mistério infinito e ilimitado. Ao contrário das ciências empíricas, na teologia não há uma apreensão do objeto conhecido, antes há uma relação com ele. Conforme Clodovis Boff chama-se de ratio fidei a sistematização em forma discursiva sobre as razões da fé, que é a teologia propriamente dita e que não esgota o mistério do divino. 4

[...] $\theta \varepsilon 0 \lambda$ o $\gamma 1 \alpha$ [teologia] é a fala narrativa sobre Deus; [...] e significa, num sentido bem geral, todo tipo de fala cujo objeto é Deus. A tarefa conferida à $\theta \varepsilon o \lambda o \gamma ı \alpha$ [teologia] é, em primeiro lugar, o vínculo praticado entre língua e Deus como aquela realidade que determina, julga e redime tudo e todos. Em seu sentido original, a teologia

(BÖTTIGHEIMER, C. Manual de teologia fundamental: a racionalidade da questão de Deus e da Revelação. Petrópolis: Editora Vozes, 2014, p.24-25).

4 "A fé feita razão, melhor ainda, feita razões, é isso precisamente a teologia. Esta nasce do intellectus fidei, para tornar-se, em seguida, a ratio fidei." (BOFF, Clodovis. Teoria do método teológico. Petrópolis: Vozes, 1998. p.71). 
significa, portanto, mais do que a fala exclusivamente objetivada sobre Deus.5

Tendo a fé em Deus como objeto a teologia procura sistematizar um discurso a partir de conceitos e linguagem humana com caráter de rigor científico. Nas ciências empíricas o objeto é conhecido, analisado e compreendido no seu todo e em suas partes e o objetivo é torná-lo parte do domínio do humano. Não ocorre o mesmo com o objeto da fé que é Deus. Na teologia, buscamos compreender "as razões de nossa esperança" ${ }^{6}$ e sistematizálas metodologicamente, no entanto não para dominar o objeto, mas para entrar em relação com este. A teologia, portanto, explicita racionalmente o que é compreensível de um mistério tocado pela fé. Nem sempre este objeto da fé poderá ser descrito, portanto, por meio de conceitos herméticos e por uma linguagem absolutamente precisa. O mistério contemplado pela teologia é sempre além, enquanto nossa linguagem permanece aquém. ${ }^{7}$

A linguagem humana se torna relativa assim para expressar o mistério, dele mais contemplamos e experimentamos do que apreendemos intelectualmente, contudo, é de considerável consenso que a linguagem possa tocar o mistério de Deus "ainda que às apalpadelas" 8 , sob forma analógica.

A possibilidade da fala adequada de Deus é negada pela chamada teologia negativa, defendida repetidamente desde os pré-socráticos. Segundo ela, a transcendência de Deus proíbe qualquer declaração positiva, i.e., afirmativa sobre Deus; dele só podemos dizer aquilo que Ele não é; não, porém, aquilo que Ele é. Desde o início, a teologia cristã tem superado essa posição num movimento de pensamento que transcende qualquer afirmação conceitual. Pois um pensamento que parte da fé não pode se satisfazer com afirmações puramente negativas. Ao contrário, elas precisam remeter de forma positiva a algo além de si mesmas, mas sem ignorar a preocupação da teologia negativa. Um caminho desse tipo foi encontrado na teoria da analogia..

\footnotetext{
5 BÖTTIGHEIMER, Christoph. Manual de teologia fundamental, p.18.

${ }^{6}$ Cf. 1 Pd 3,15.

7 "Pelo fato de a fé não evocar seu objeto 'Deus' primeiro por conceitos, mas por meio de símbolos, e pelo fato de a vida religiosa não se desdobrar primeiramente em análises e reflexões, mas no testemunho, na confissão e no rito, a proclamação de Deus precede tanto objetiva como temporalmente o ensino sistemático elaborado de Deus ou do divino." (BÖTTIGHEIMER, C. Manual de teologia fundamental, p.19).

8 Cf. At 17,27 .

9 BÖTTIGHEIMER, C. Manual de teologia fundamental, p.25.
} 


\subsection{A Analogia entis como discurso sobre Deus}

Segundo Anzenbacher "O discurso analógico fala do desconhecido a partir do conhecido, [...]. Portanto, refere-se ao desconhecido falando do conhecido.”10 Trata-se de aplicar uma linguagem metafórica, atribuindo predicações a Deus a partir das criaturas. No entanto, “[...] nunca é capaz de dizer o que o desconhecido seria em si." ${ }^{11}$. Tomás de Aquino foi o grande entusiasta do discurso analógico sobre Deus, afirma a sua possibilidade e validade na atribuição de predicados a Deus sob a forma de proporcionalidade para com as criaturas.

[...] Portanto, nenhum nome é atribuído univocamente a Deus e à criatura. Mas também não é atribuído de maneira completamente equívoca como alguns o disseram. Nesse caso, nada se poderia conhecer de Deus a partir das criaturas, nada demonstrar a seu respeito; sempre se cairia na falácia da equivocidade. Isso vai contra o testemunho tanto dos filósofos que demonstraram muitas coisas a respeito de Deus, quanto do próprio Apóstolo, dizendo aos Romanos: 'Perfeições invisíveis de Deus se tornam conhecidas por suas obras'. É preciso dizer que os nomes em questão são atribuídos a Deus e às criaturas segundo analogia, isto é, segundo proporção. ${ }^{12}$

O homem pode, portanto, de acordo com o pensamento de Tomás de Aquino, chegar a algum conhecimento de Deus, ainda que de modo parcial e com proporcionalidade, a partir das criaturas, porque estas estão referidas ao seu Criador. "[...] Deve haver, portanto uma certa semelhança entre o Criador e as criaturas" ${ }^{13}$, afirma Luis F. Ladaria, contudo, essa semelhança não identifica totalmente, mas apenas metaforicamente, pois “[...] a dessemelhança entre ambos é ainda maior" ${ }^{14}$. O livro da Sabedoria ${ }^{15}$ alude para a capacidade do homem reconhecer nas criaturas, traços do Criador, tal como a partir da obra de um artista se pode intuir a autoria. Trata-se de um conhecimento por analogia da qual fala o doutor angélico.

\footnotetext{
${ }^{10}$ ANZENBACHER, A. Einführung in die Philosophie, 2002. In: BÖTTIGHEIMER, C. Manual de teologia fundamental, p.25.

${ }^{11}$ ANZENBACHER, A. Einführung in die Philosophie, 2002. In: BÖTTIGHEIMER, C. Manual de teologia fundamental, p. 25.

12 S.Th. I, q. 13, a. 5 .

${ }^{13}$ LADARIA, Luis F. O Deus vivo e verdadeiro: o mistério da Trindade. São Paulo: Loyola, 2005, p. 406.

${ }_{14}^{4}$ LADARIA, Luis F. O Deus vivo e verdadeiro, p. 406.

${ }_{15}$ "Sim, naturalmente vãos foram todos os homens que ignoraram a Deus e que, partindo dos bens visíveis, não foram capazes de conhecer Aquele que é, nem considerando as obras, de reconhecer o Artífice.” (Sb 13,1).
} 
A esse conhecimento [de Deus] podia-se chegar por comparação, semelhança, proporção, a partir das coisas criadas que ele fez; evidentemente, no discurso teológico, a 'analogia', enquanto nela entra Deus, tem que se relacionar com a criação. Em virtude dela, a criatura se acha em relação a Deus. ${ }^{16}$

Conforme Böttigheimer, "a fala analógica expressa, por meio da comparação, a igualdade e diferença, e assim remete ao indefinido." ${ }^{17}$. No discurso analógico se diz tanto o que é próximo entre os objetos comparados quanto o que se distancia. Abrange de forma inclusiva, portanto, o dizer apofático da teologia, ainda que indiretamente, isto é, fala afirmativamente sobre Deus, preservando aquilo que não é possível predicar-lhe. "A analogia inicia um movimento que parte da afirmação positiva e passa por sua purificação para almejar aquilo que tudo supera." $18 \mathrm{O}$ autor Ladaria 19 nos aponta que os conceitos humanos são insuficientes para expressar o mistério de Deus, contudo ainda assim são eficazes no sentido de que nos abrem para aquilo que transcende o pensamento e a própria linguagem humana. Também nos dá precisão no tipo de analogia que pode ser aplicada pela linguagem humana para dizer sobre Deus. Se diz que "A está para B como C está para D. [...] o ocaso é para o dia o que a velhice é para a vida” ${ }^{20}$, neste exemplo elucidando a analogia de proporcionalidade.

[...] Não há comparação possível entre o Criador infinito, que cria em sua onímoda liberdade, e a criatura que só existe em referência a Deus. Não podemos abarcar os dois em um conceito comum nem com nosso pensamento nem com nossas palavras. Portanto, a analogia assim entendida não significa abraçar Deus e a criatura em um mesmo conceito e em uma mesma linguagem, mas precisamente remeter-nos ao mistério, ao que está mais além de nós mesmos. ${ }^{21}$

\subsection{Falar de Deus a partir das causas eficientes e finais}

Santo Agostinho, filósofo e teólogo do século IV, também descreveu a possibilidade do homem encontrar os vestígios da divindade invisível na criação

\footnotetext{
${ }^{16}$ LADARIA, Luis F. O Deus vivo e verdadeiro, p. 401.

17 BÖTTIGHEIMER, C. Manual de teologia fundamental, p.26.

${ }_{18}$ BÖTTIGHEIMER, C. Manual de teologia fundamental, p.27.

19 “[...] Assim não há perigo de fazer Deus objeto de conceitos humanos que abarquem ao mesmo tempo Deus e a criatura. A analogia não torna vã toda linguagem humana sobre Deus, mas em último termo remete a seu mistério. Trata-se de um processo que ao final não nos mostra um termo preciso, senão que nos abre para quem é maior do que nossa palavra e nosso pensamento." (LADARIA, Luis F. O Deus vivo e verdadeiro, p. 406).

${ }^{2}$ LADARIA, Luis F. O Deus vivo e verdadeiro, p. 405.

${ }^{21}$ LADARIA, Luis F. O Deus vivo e verdadeiro, p. 406.
} 
visível. Böttingheimer apresenta o pensamento de Agostinho e ao mesmo tempo comenta-o elucidando como no próprio ato de conhecimento do divino a partir das criaturas se fazem presente as três formas de discurso teológico.

\footnotetext{
'Tu, então, Senhor, os [o céu e a terra] criaste, Tu, que és formoso - pois eles são formosos; Tu, que és bom - pois eles são bons; Tu, que és - pois eles são [via affirmativa]. Porém, não são formosos, nem são bons, nem são como Tu, seu Criador [via negativa], comparados com o qual não são nem formosos, nem bons, nem são [via eminentiae]'.22
}

De maneira semelhante Tomás de Aquino propôs cinco vias da existência de Deus, partindo das causas eficientes e causas finais, postulando analogamente a partir das criaturas e das leis naturais, Deus como o Primeiro Motor, a Causa Causante Incausada, o Ser necessário, a Suma perfeito, o Ato Puro Ordenador para onde tudo se ordena. ${ }^{23}$ Partindo da autoridade destes pensadores teólogos, a tradição cristã afirma "que Deus, a origem e o alvo de todas as coisas, certamente pode ser conhecido com a luz natural da razão humana a partir das coisas criadas"24. No entanto, ainda assim, os postulados racionais $\mathrm{e}$ as analogias de proporcionalidade apesar de ser uma forma de dizer algo de Deus, não podem dizer o indizível: “[...] No fim do pensamento analógico está, portanto, a incompreensibilidade de Deus [...]”..25.

\section{A Teologia da cruz como revelação de Deus}

Vimos até aqui que há uma linguagem que expressa os atributos divinos a partir da analogia entis ou de proporcionalidade. Mas também vimos que encontramos um limite de tal discurso para falar de Deus em si mesmo. É possível dizer mais sobre Deus? Para transpor essa questão passaremos a aprofundar o dado do discurso da revelação sobrenatural sobre Deus a partir da teologia da cruz com

\footnotetext{
${ }^{22}$ AGOSTINHO. Confissões. XI, IV.6 (CCSL 27, 1970). In: BÖTTIGHEIMER, C. Manual de teologia fundamental, p.27.

${ }^{23}$ S.Th I, q. 2, a. 3.

24 DEZINGER, H. \& HÜNERMANN, P. (orgs.). Enchiridion symbolorum definitionum et declarationum de rebus fidei et morum. Kompendium der Glaubensbekenntnisse und kirchlichen Lehrentscheidungen. Friburgo i. Br, p. 3004. In: BÖTTIGHEIMER, C. Manual de teologia fundamental, p.258.

25 BÖTTIGHEIMER, C. Manual de teologia fundamental, p. 27.
} 
base em alguns excertos de Jürgen Moltmann ${ }^{26}$ e Edith Stein no intuito de dar um passo adiante daquele dado pela analogia entis.

Para Moltmann, Tomás de Aquino, realiza uma grande contribuição para um discurso natural sobre Deus, contudo não chega a dizer algo sobre a identidade de Deus. Acerca disto, para introduzir seu pensamento sobre a teologia da cruz, escreve:

[...] Tomás, com isso, dá uma resposta à pergunta: O que é o divino? - mas não responde à pergunta: Quem é Deus? Em virtude daquelas suas provas, tornou-se possível pensar e Deus como o ser supremo, contudo, nada nos obriga a chamar a essa substância suprema 'Deus'. O fato de que 'todos' os homens 'chamam de Deus' a essa substância é devido ao consensus gentium, o qual, segundo o próprio Tomás, não é obrigatório, mas apenas representa, segundo as circunstâncias, uma regulação linguística relativamente comum. ${ }^{27}$

Moltmann chama moldura toda a construção da teologia natural, nas vias cosmológicas, que predica a Deus propriedades metafísicas como ser de substância suprema, o motor imóvel, ser uno e necessário, ordenador e autor da perfeição de todos os seres, impassível, etc. Para o autor, “[...] a doutrina de Deus, especificamente cristã, não pode alterar esse quadro, embora deva ocupar-se tanto do Deus uno e trino como da paixão do Filho de Deus na cruz." ${ }^{28}$. A moldura enquadra a obra como tal que nos é expressa através da cruz. Em sua obra Trindade e Reino de Deus dedica um capítulo para apresentar um Deus cristão marcado não pelos atributos clássicos do divino, mas antes pela experiência do sofrimento intrínseco ao amar. Deus é passível porque ama. Esse tipo de predicação de Deus só nos pode ser elucidado a partir da revelação da cruz. ${ }^{29}$

Outra autora que entende a cruz como lugar privilegiado para falar e predicar algo sobre Deus é Edith Stein ${ }^{30}$, filósofa fenomenóloga e teóloga, dos

\footnotetext{
${ }^{26}$ Jürgen Moltmann é um teólogo alemão, nascido em 1926 na cidade de Hamburgo. Doutor em teologia em 1952 e foi professor em diversas Universidades como Wuppertal, Bonn e Tübingen. Conhecido como o teólogo da esperança desenvolveu temas teológicos com preocupações com os problemas sociais e ambientais. (Nota do autor).

${ }_{27}$ MOLTMANN, Jürgen. Trindade e Reino de Deus: uma contribuição para a teologia. 2.ed. Petrópolis: Vozes, 2011, p. 26.

${ }_{28}^{28}$ MOLTMANN, J. Trindade e Reino de Deus, p. 31.

${ }^{29}$ A temática abordada é refletida no capítulo II do livro: MOLTMANN, J. Trindade e Reino de Deus. $3^{30}$ Edith Stein nasceu em Breslau [Alemanha] em 12 de outubro de 1891 de família e religião judia, converteu-se ao cristianismo após um processo que passara desde a fenomenologia de Husserl até o estudo da Escolástica em Tomás de Aquino e a leitura da vida de Santa Teresa D’Ávila. Contribuiu valiosamente para a antropologia cristã com sua tese doutoral sobre a temática da empatia em 1916. Após sua conversão ao cristianismo tornou-se monja carmelita e mais tarde foi presa e morta pelo regime nazista, na câmara de gás, durante a II Guerra Mundial em 9 de agosto de 1942. (Cf. SÁNCHEZ MUÑOZ, Rubén. Edith Stein: Las etapas de su evolución personal e intelectual. Persona, Córdoba, n. 22, p. 39-48, abr.2013).
} 
séculos XIX e XX. A partir da visão de Virgínia Raquel Azcuy, Edith Stein possui “[...] uma forte concentração soteriológica que evidencia sua opção por uma 'theologia crucis';”31.

Quando falamos da ciência da cruz, ela não deve ser entendida no sentido usual da ciência: não é uma teoria simples, isto é, não é uma mera conexão de afirmações verdadeiras - reais ou da razão - não é uma construção idealmente desenvolvida de passos lógicos de pensamento. Ela é a verdade reconhecida - uma teologia da cruz-, mas uma verdade viva, real e eficaz: ela afunda na alma como uma semente, enraíza e cresce, dá à alma um selo especial e a determina em seu fazer e deixar, de tal maneira que ela possa irradiar e ser reconhecida por este fazer e deixar. Nesse sentido se fala de uma ciência dos santos e nós falamos da ciência da cruz. ${ }^{2}$

\section{A fenomenóloga cristã nos coloca diante de Deus como o Teólogo} primordial. Quando se predica algo sobre Deus, é Ele próprio quem permite que a linguagem seja capaz de expressá-Lo. No entanto, o discurso mais eficaz sobre Deus não é propriamente aquele expresso em linguagem, mas aquele que é simplesmente vivido e contemplado. O melhor discurso sobre Deus é o calar, o silêncio contemplativo, de quem se coloca diante do mistério indizível. O silêncio religioso comunica o indizível de Deus.

Deus é o teólogo primordial. Todo falar acerca de Deus pressupõe um
falar do próprio Deus. Seu falar mais próprio, diante do qual a
linguagem humana deve calar não se ajusta a nenhuma palavra humana
ou a qualquer linguagem da imagem. [...] Ele dá a seus teólogos as
palavras e as imagens, o que lhes permite falar Dele para os outros. E
Ele fala aos outros como 'teólogo simbólico' - através da natureza, por
meio da experiência interna e por seus traços na existência humana e
nos eventos do mundo - e, assim, permite que esses outros entendam a
linguagem dos teólogos.33

${ }_{31}$ "[...] uma fuerte concentración soteriológica que evidencia su opción por uma 'theologia crucis';" (AZCUY, Virginia Raquel, Una teología epifánica, eficaz y discreta. Diálogo entre Edith Stein y la teología contemporanea. Teresianum, Buenos Aires, n.50, p.61-85, jan/fev.1999, p. 71) (Tradução nossa).

${ }_{32}$ "Cuando hablamos de ciencia de la cruz, no ha de entenderse en el sentido habitual de ciencia: ella no es una simple teoría, es decir, no es una mera conexión de afirmaciones verdaderas - reales o de razón -, no es una construcción ideal desarrollada a partir de pasos lógicos del pensamiento. Ella es la verdad reconocida - una teología de la cruz -, pero una verdad viviente, real y eficaz: se hunde en el alma como una semilla, echa raíces y crece, da al alma un sello especial y la determina en su hacer y dejar, de modo tal que pueda irradiarse y ser reconocida a partir de este hacer y dejar. En este sentido se habla de una ciencia de los santos y nosotros hablamos de la ciencia de la cruz." (STEIN, Edith. Kreuzeswissenschaft. Apud: AZCUY, Virginia Raquel, Una teología epifánica, eficaz y discreta. Diálogo entre Edith Stein y la teología contemporanea. Teresianum, Buenos Aires, n.5o, p.61-85, jan/fev.1999, p. 75) (Tradução nossa).

33 "Dios es el Teólogo primordial. Todo hablar acerca de Dios presupone un hablar de Dios mismo. Su hablar más propio, ante el cual el lenguaje humano debe callar, no se ajusta a ninguna palabra humana ni a ningún lenguaje de la imagen. [...] Él da a sus teólogos las palabras y las imágenes, lo cual les posibilita hablar de Él a otros. Y Él habla a los otros como 'teólogo simbólico' -a través de la naturaleza, por la experiencia interna, y por sus huellas en la existencia humana y en el acontecer 
O falar próprio de Deus nos é dado pelo falar do Verbo Divino. Para Edith Stein, "se agora desejássemos seguir teologicamente o pensamento 'Deus - o teólogo primordial', deveríamos tomar como fundamento [...] o falar do Verbo Divino.”34. O Verbo Divino encarnado une palavra e vida na sua entrega na cruz. A teologia que emerge da cruz nos apresenta, portanto, um novo modo de falar de Deus, que só será compreendido se advir da experiência da contemplação e do silêncio perante a entrega do Verbo na cruz. A cruz fala por si mesma e condensa no gesto do Verbo toda a fala de Deus acerca de si mesmo, enquanto teólogo primordial.

Em síntese, a ciência teológica de Teresa Benedita se expressa como uma ciência esponsal que se desdobra na dinâmica do seguimento e do amor a cruz, e ao mesmo tempo, como uma ciência universal porque a força da cruz está em todas as frentes e lugares de aflição. 35

A experiência da contemplação e do silêncio diante da cruz se torna, portanto, verdadeira comunicação da identidade de Deus. Em outras palavras se torna uma linguagem toda própria e particular para dizer acerca do mistério de Deus que convida ao seguimento.

\section{O limite da teologia ocidental para dizer a Pessoa de Deus}

O que foi abordado até aqui nos permite falar dos limites da linguagem e do discurso teológico clássico para corresponder à identidade divina. Vimos que o discurso analógico sobre Deus diz afirmativamente algo sobre Deus, preservando a via negativa indiretamente, à medida que pode proporcionalizar os predicados racionais e naturais a respeito do mistério transcendente, mas apesar disso, não é capaz de referenciá-lo pessoalmente. O que não foi possível ser dito de Deus pela

del mundo-, y posibilita así que estos otros entiendan el lenguaje de los teólogos." (STEIN, Edith. Gesammelte Werke. Apud: AZCUY, Virginia Raquel, Una teología epifánica, eficaz y discreta.

Diálogo entre Edith Stein y la teología contemporanea. Teresianum, Buenos Aires, n.50, p.61-85, jan/fev.1999, p. 79) (Tradução nossa).

34 "Si quisiéramos seguir ahora teológicamente el pensamiento 'Dios - el Teólogo primordial', deberíamos tomar como fundamento lo realmente más propio del hablar de Dios, el hablar de la Palabra Divina. Como Símbolo primordial habría que tener ante los ojos la Palabra hecha carne." (STEIN, Edith. Gesammelte Werke. Apud: AZCUY, Virginia Raquel, Una teología epifánica, eficaz y discreta. Diálogo entre Edith Stein y la teología contemporanea. Teresianum, Buenos Aires, n.5o, p.61-85, jan/fev.1999, p. 80) (Tradução nossa).

35 "En síntesis, la ciencia teológica de Teresa Benedicta se expressa como una ciencia esponsal que se despliega en la dinámica del seguimiento y del amor a la cruz, y a la vez, como una ciencia universal porque en la fuerza de la cruz está en todos los frentes y lugares de aflicción.” (AZCUY, Virginia Raquel, Una teología epifánica, eficaz y discreta. Diálogo entre Edith Stein y la teología contemporanea. Teresianum, Buenos Aires, n.50, p.61-85, jan/fev.1999, p. 77) (Tradução nossa). 
analogia da linguagem teológica, foi aprofundado pelo que é dito no acontecimento da cruz. A experiência do silêncio e da contemplação diante da cruz comunicam como que novos predicados para Deus dizendo-os não de forma análoga, mas de maneira catafática e mística. ${ }^{36}$

Ainda assim, nenhuma das expressões teológicas enquanto se expressam por meio de uma linguagem, são por si mesmas suficientes para falar com sentido pleno sobre Deus. Precisamos concluir que nem a analogia entis nem a teologia da cruz bastam para elucidar o mistério divino, uma vez que poderíamos lançar questionamentos também sobre os limites da teologia da cruz, o que não fazemos aqui nesta breve pesquisa. No entanto, podemos afirmar que a teologia da cruz toca mais intimamente o que Deus revela não com palavras, mas com o seu gesto, a respeito de si próprio.

Se na Modernidade acreditava-se na referencialidade direta entre conceitos e mundo (signos e realidade), com os novos estudos linguísticos surge a denúncia a respeito da fissura e descontinuidade entre coisa e palavra, revelando-nos as limitações das metanarrativas e suas derivações. 37

Ambas as formas de discursos teológicos são limitados e igualmente complementares. À medida que a própria capacidade da linguagem em expressar o real é posta sob suspeita, conforme visto acima com Kenner Terra, a linguagem teológica também permanecerá aquém da totalidade do mistério, não só por este último ser insondável, mas pelos próprios limites da linguagem. No entanto, também exerce com sucesso sua função à medida que nos coloca em relação com o mistério, nos possibilita o frente a frente da contemplação onde a linguagem do silêncio é que discursa e comunica.

\footnotetext{
36 "De fato deve ser atribuído à revelação divina que aquilo que das coisas divinas não é acessível à razão humana em si, também na presente condição do gênero humano pode ser conhecido por todos sem dificuldade, com segura certeza. Entretanto, não é por esta razão que a revelação deve ser declarada estritamente necessária, mas porque Deus, com base em sua bondade infinita, destinou o ser humano a um fim sobrenatural, ou seja, a participar dos bens divinos que excedem totalmente a capacidade de conhecimento do espírito humano; pois 'nenhum olho viu, nenhum ouvido ouviu, nem atingiu o coração de uma pessoa humana o que Deus preparou para aqueles que o amam' (1Cor 2,9)." (DEZINGER, H. \& HÜNERMANN, P. (orgs.). Enchiridion symbolorum definitionum et declarationum de rebus fidei et morum. Kompendium der Glaubensbekenntnisse und kirchlichen Lehrentscheidungen. Friburgo i. Br, p. 3008. In: BÖTTIGHEIMER, C. Manual de teologia fundamental: a racionalidade da questão de Deus e da Revelação. Petrópolis: Editora Vozes, 2014, p.261).

37 TERRA, Kenner Roger Cazotto. Teorias da linguagem e estudos do discurso: apontamentos metodológicos para uma análise do discurso religioso. Horizonte, Belo Horizonte, v. 16, n.51, p.10851106, set./dez. 2018, p. 1086.
} 


\section{Conclusão}

Ao chegarmos ao termo da afirmação de que a linguagem é insuficiente para dizer o mistério de Deus, quer seja na sua maneira de dizê-lo, quer pelo objeto divino que lhe transcende e escapa enquanto mistério ou ainda quer pelo limite intrínseco da própria linguagem, nem por isso concluímos que a teologia seja incapaz de dizêlo de alguma maneira. Ao contrário, a analogia entis de Tomás de Aquino e a linguagem contemplativa da cruz completam-se mutuamente e joga o ser humano para a experiência do mistério transcendente.

À medida que analogia entis e teologia da cruz se caracterizam como linguagem teológica, também o que se diz sobre Deus possui o intuito não de domínio ou apreensão do objeto, mas de colocar-se em relação com ele. A linguagem cumpre aqui a missão, não de descrição rígida do mistério, mas de propiciar o encontro do humano com este.

\section{Referências}

AGOSTINHO. Confissões. XI, IV.6 (CCSL 27, 1970). In: BÖTTIGHEIMER, C. Manual de teologia fundamental: a racionalidade da questão de Deus e da Revelação. Petrópolis: Editora Vozes, 2014.

ANZENBACHER, A. Einführung in die Philosophie, 2002. In: BÖTTIGHEIMER, C. Manual de teologia fundamental: a racionalidade da questão de Deus e da Revelação. Petrópolis: Editora Vozes, 2014.

AQUINO, Tomás de. Suma Theologica.v. I, parte I. 2.ed. São Paulo: Edições Loyola, 2001.

AZCUY, Virginia Raquel, Una teología epifánica, eficaz y discreta. Diálogo entre Edith Stein y la teología contemporanea. Teresianum, Buenos Aires, n.50, p.61-85, jan/fev.1999.

BOFF, Clodovis. Teoria do método teológico. Petrópolis: Vozes, 1998.

BÖTTIGHEIMER, C. Manual de teologia fundamental: a racionalidade da questão de Deus e da Revelação. Petrópolis: Editora Vozes, 2014.

DEZINGER, H. \& HÜNERMANN, P. (orgs.). Enchiridion symbolorum definitionum et declarationum de rebus fidei et morum. Kompendium der Glaubensbekenntnisse und kirchlichen Lehrentscheidungen. Friburgo i. Br, p. 3008. In: BÖTTIGHEIMER, C. Manual de teologia fundamental: a racionalidade da questão de Deus e da Revelação. Petrópolis: Editora Vozes, 2014. 
JOÃO PAULO II. Mensagem do Papa João Paulo II aos teólogos, filósofos e peritos participantes no Congresso Internacional Tomista. Roma, 2003. Disponível em: http://www.vatican.va/content/john-paul-ii/pt/speeches/2003/congressotomista.pdf. Acesso em: 08 de jun. de 2020.

LADARIA, Luis F. O Deus vivo e verdadeiro: o mistério da Trindade. São Paulo: Loyola, 2005.

MOLTMANN, Jürgen. Trindade e Reino de Deus: uma contribuição para a teologia. 2.ed. Petrópolis: Vozes, 2011.

SÁNCHEZ MUÑOZ, Rubén. Edith Stein: Las etapas de su evolución personal e intelectual. Persona, Córdoba, n. 22, p. 39-48, abr.2013.

STEIN, Edith. Gesammelte Werke. Apud: AZCUY, Virginia Raquel, Una teología epifánica, eficaz y discreta. Diálogo entre Edith Stein y la teología contemporanea. Teresianum, Buenos Aires, n.50, p.61-85, jan/fev.1999.

TERRA, Kenner Roger Cazotto. Teorias da linguagem e estudos do discurso: apontamentos metodológicos para uma análise do discurso religioso. Horizonte, Belo Horizonte, v. 16, n.51, p.1085-1106, set./dez. 2018.

Recebido em: 21/07/2019. Aprovado em: 27/07/2020. Publicado em: 28/07/2020. 